\title{
AS INTERFERÊNCIAS DO PROCESSO PRODUTIVO NA CONCEPÇÃO DE PROJETO DE EDIFÍCIOS EM CLT - CROSS LAMINATED TIMBER
}

\author{
OLIVEIRA, Gabriela Lotuffo (1); OLIVEIRA, Fabiana Lopes de (2)
}

(1) Mestranda do curso de Pós Graduação da Faculdade de Arquitetura e Urbanismo da Universidade de São Paulo, gabriela.lotuffo.oliveira@usp.br; (2) Professora do Departamento de Tecnologia da Arquitetura, Faculdade de Arquitetura e Urbanismo da Universidade de São Paulo, floliveira@usp.br

Resumo: Prevalece no Brasil a adoção de técnicas construtivas tradicionais, que carecem de avanços tecnológicos e ocasionam grande impacto ambiental. Em contraposição a esse cenário nacional, iniciouse no país, há pouco mais de quatro anos, a produção de um componente desenvolvido inicialmente na Europa, na década de 1990, denominado Cross Laminated Timber (CLT). Esse sistema construtivo inovador, baseado no uso da madeira maciça, associa a madeira (matéria-prima que pode ser considerada como um dos poucos materiais de construção de fato renovável) às técnicas contemporâneas de industrialização. Os painéis de CLT compõem-se de números ímpares de camadas de lâminas de madeira maciça dispostas em direções cruzadas e entremeadas com adesivo estrutural. Podem atingir comprimento de até $12 \mathrm{~m}$ e largura de até $3 \mathrm{~m}$. A laminação cruzada melhora suas propriedades estruturais, possibilitando seu emprego como lajes (pisos e forros), paredes autoportantes e outros elementos estruturais ou de vedação. Podem ser cortados em fábrica em diferentes formatos, adequando-se a qualquer projeto arquitetônico. Da mesma maneira, aberturas de portas, janelas ou mesmo canaletas de passagem de eletrodutos, também podem ser executadas previamente em fábrica. Ressalta-se, nesse sentido, que as etapas integrantes deste sistema construtivo se inter-relacionam e devem ser pensadas e planejadas conjuntamente, de maneira otimizada, para o melhor aproveitamento dos conceitos de racionalização que o sistema oferece. Assim, o presente artigo visa apresentar todo o processo de produção dos painéis CLT, destacando as principais decisões de projeto que impactam na fase de confecção dos mesmos. $O$ método da pesquisa consistiu em revisão bibliográfica sobre o tema, concepção de projetos em CLT e acompanhamento da produção dos painéis, além de visitas a obras de edificações em CLT. Os resultados deste trabalho permitem a maior difusão das informações no que concerne ao uso do CLT e ao processo de projeto para esta inovadora tecnologia construtiva.

Palavras-chave: Cross Laminated Timber (CLT), sistema construtivo inovador, construção industrializada, projeto arquitetônico.

Área do Conhecimento: Tecnologia de Processos e Sistemas Construtivos - Processo de Produção

\section{INTRODUÇÃO}

Prevalece ainda no Brasil a lógica da construção convencional, pautada no uso predominante da alvenaria e do concreto. Entretanto, adotando sistemas construtivos convencionais, o setor da construção civil apresenta hoje um grande desperdício de recursos e uma produtividade destacadamente inferior em comparação a outros setores (SABATTINI, 1989). É, assim, um dos maiores responsáveis pela geração de resíduos sólidos e pela emissão de gases que causam o efeito estufa, sendo também responsável por uma grande parcela do consumo de recursos naturais, dentre eles, água e energia. O volume de resíduos gerado é agravado pelas perdas nos processos ainda não otimizados, que carecem de avanços tecnológicos.

É evidente, portanto, a necessidade de se introduzirem inovações no setor que modifiquem a abordagem da construção, garantindo a evolução contínua da tecnologia e a modernização da indústria. Nessa perspectiva, sistemas construtivos industrializados representam uma excelente alternativa (SABATTINI, 1989). A industrialização e a racionalização no campo da construção civil apresentam vantagens amplamente conhecidas, porém pouco aplicadas. Como exemplo, a pré-fabricação bem planejada pode ajudar a reduzir os prazos de execução da obra, a eliminação do desperdício de materiais 
e, consequentemente, a redução nos custos da construção, garantindo a qualidade dos componentes e a segurança construtiva. Além disso, tecnologias construtivas industrializadas são compreendidas como aliadas no combate à degradação ambiental, considerando-se a significativa redução na produção de resíduos nos canteiros, o que as torna menos poluentes (BRUNA, 2002).

Dentre os materiais que possibilitam essa industrialização, encontra-se a madeira e seu emprego em técnicas construtivas industrializadas contemporâneas, como wood-frame, estruturas em Madeira Laminada Colada (MLC) ou mesmo o Cross Laminated Timber (CLT). O uso do CLT está consolidado na Europa. Na América do Norte, é um material que se encontra em fase de implementação, mostrandose como uma alternativa viável aos sistemas em madeira (wood-frame) já largamente utilizados na região (KARACABEYLI; DOUGLAS, 2013). No Brasil, a norma técnica sobre esses sistemas construtivos em madeira leve (wood-frame) encontra-se em fase de elaboração (VAZ, 2017). Aqui, a produção de CLT ainda é muito recente, tendo sido iniciada há cerca de quatro anos, e, até o momento, tem-se conhecimento de apenas um fabricante, que iniciou sua produção em 2012. Nesse mesmo ano, foi edificada a primeira residência em CLT no Brasil. Não foram encontrados outros fabricantes ou exemplos de edificações construídas antes dessa data.

Portanto, com o objetivo de gerar subsídios para o desenvolvimento de projetos arquitetônicos nos quais poderá ser empregada essa inovadora tecnologia construtiva, o presente artigo visa apresentar todo o processo de produção de painéis CLT, destacando as principais decisões de projeto que impactam na fase da sua concepção. A metodologia adotada consistiu em revisão bibliográfica sobre o tema, concepção de projetos em CLT, acompanhamento da produção dos painéis e visitas a algumas obras de edificações em CLT.

\section{CROSS LAMINATED TIMBER (CLT)}

\subsection{O sistema construtivo}

O CLT, ou madeira laminada colada cruzada, foi desenvolvido inicialmente na Suíça e na Áustria, na década de 1990, como consequência de uma ação conjunta entre a indústria e o meio acadêmico (SILVA; BRANCO; LOURENÇO, 2012). No entanto, somente após alguns anos, a demanda por esse produto passou a se tornar de fato significativa, tendo em vista que, inicialmente, informações acerca do desempenho do CLT ainda eram escassas (STAUDER, 2013).

O nome "madeira laminada colada cruzada" provém da composição e da forma com a qual esse sistema é executado. Para a produção de CLT, as lâminas de madeira maciça são coladas lado a lado formando camadas dispostas ortogonalmente (Figura 1). Os painéis podem conter entre três e sete camadas, sempre em número ímpar, de modo a se criar um eixo de simetria na camada central. Ainda que suas dimensões possam ser ajustadas de acordo com o projeto arquitetônico, há limitações dimensionais, que variam de acordo com cada fabricante: os painéis podem ser produzidos com largura e comprimento máximos de $3 \mathrm{~m}$ e $18 \mathrm{~m}$ respectivamente, e com espessura entre $57 \mathrm{~mm}$ e $400 \mathrm{~mm}$.

Figura 1 - Esquema de montagem de um painel de CLT
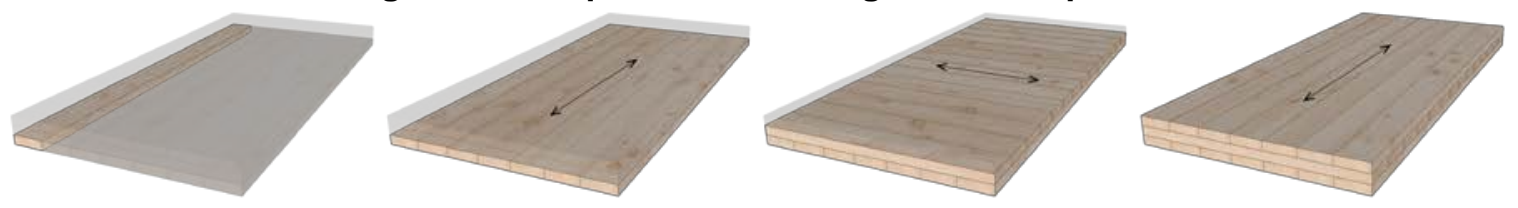

Fonte: da autora (2017)

A laminação cruzada dos painéis melhora suas propriedades estruturais, possibilitando a distribuição dos esforços ao longo das fibras da madeira em direções distintas. Sua principal inovação é, portanto, a produção de elementos em painéis (COSTA, 2013), que podem ser empregados como lajes (pisos e forros), paredes autoportantes, divisórias internas entre ambientes, dentre outros elementos estruturais ou de vedação. O campo de aplicação desse sistema construtivo abrange, praticamente, todo o setor de edificações, como edifícios residenciais, comerciais, escolares e hospitalares. 


\subsection{Algumas considerações sobre o sistema construtivo}

O uso do CLT como sistema construtivo, assim como outros sistemas industrializados de construção, apresenta vantagens e desvantagens que devem ser consideradas com relação à edificação a ser construída.

Dentre as vantagens, pode-se citar prontamente a diminuição do tempo de execução da obra, redução dos resíduos gerados no canteiro, dentre outras já mencionadas anteriormente. Além disso, a madeira pode ser considerada um dos poucos materiais de construção de fato renováveis, apresentando baixo consumo energético para sua produção, quando comparada a outros materiais (MOLINA; CALIL JUNIOR, 2010). Sua utilização também se mostra muito benéfica para o meio ambiente. Durante o crescimento, as árvores absorvem e fixam o gás carbônico por meio da fotossíntese, e o $\mathrm{CO}_{2}$ absorvido será lançado novamente à atmosfera apenas ao final do ciclo de vida dessas árvores, seja por meio da decomposição ou da combustão da madeira. Logo, a utilização da madeira na construção civil, impedindo sua decomposição, impede a liberação do $\mathrm{CO}_{2}$, sendo assim, considerada um meio eficiente de combate ao efeito estufa, que é ocasionado pelo aumento da taxa de $\mathrm{CO}_{2}$ na atmosfera, e causa das alterações climáticas do planeta (GAUZIN-MÜLLER, 2011).

Outra vantagem relacionada ao sistema consiste na alta precisão dimensional dos painéis, proveniente da fabricação industrial e da usinagem em um equipamento com Comando Numérico Computadorizado (CNC). Os painéis chegam ao canteiro prontos para serem fixados no local definitivo, inclusive com aberturas e outras providências para instalações prediais já realizadas. As grandes dimensões das peças e o processo de pré-fabricação possibilitam, dessa forma, uma construção rápida, simples e silenciosa, reduzindo o número de possíveis fontes de erros durante a montagem e a produção de resíduos em obra. O tempo de montagem de uma edificação em CLT é dimensionado em dias.

Apesar dos aspectos positivos associados ao sistema, observam-se algumas restrições, em especial no que diz respeito ao uso da madeira como elemento estrutural. Uma das maiores dificuldades consiste em combater o preconceito errôneo que considera que estruturas em madeira possuem resistência ao fogo inferior a outras soluções construtivas convencionais, como, por exemplo, estruturas em aço (SILVA; BRANCO; LOURENÇO, 2012). Sistemas estruturais em madeira maciça e espessa proporcionam, na realidade, excelente resistência ao fogo, quando comparados a outros materiais estruturais, isto em razão de seu lento processo de carbonização. Peças robustas, quando expostas ao fogo, formam uma camada de carvão isolante em seu perímetro externo, mantendo o interior praticamente intacto. Portanto, sistemas maciços em madeira, nos quais pode ser incluído o CLT, mantêm grande parte de sua capacidade estrutural por períodos extensos sob a ação das chamas (MOLINA; CALIL JUNIOR, 2010). De modo a comprovar a resistência ao fogo, foi realizado em Tsukuba, no Japão, no ano de 2008, um teste de incêndio em escala real em um edifício de três pavimentos construído em CLT. O fogo iniciado em apenas um dos ambientes pôde ser extinguido manualmente após 60 minutos, sem que houvessem ocorrido danos estruturais nos painéis ou mesmo difusão do incêndio a outros ambientes do edifício (FRANGI; BOCHICCHIO; CECCOTTI; LAURIOLA, 2008).

Outro requisito muito questionado quando se trata do material "madeira" é a sua resistência à deterioração. Essa resistência pode ser entendida como a capacidade intrínseca de uma determinada espécie de resistir à ação de agentes deterioradores, incluindo-se neles tanto agentes biológicos como físicos e químicos. No Brasil, um país tropical com condições macro e microclimáticas para o desenvolvimento de fauna e flora, a deterioração causada por agentes biológicos, ou seja, o processo de biodeterioração da madeira, é extremamente relevante. Nesse sentido, é necessário recorrer ao tratamento preventivo adequado à matéria- prima, visando à durabilidade e à preservação dos elementos estruturais, de modo a proteger a madeira contra fungos apodrecedores e emboloradores e insetos xilófagos, como os cupins e brocas de madeira. A preservação química ainda é a forma mais usual na prevenção do ataque biológico, e um dos métodos mais eficientes consiste na aplicação, em autoclave, do preservante químico nos sarrafos de madeira. Dentre os preservantes mais usuais encontram-se o CCA-C (arseniato de cobre cromatado - tipo C) e o CCB (borato de cobre cromatado) (BARILLARI; FREITAS, 2002).

Também, especificamente no caso da produção nacional, tem-se que considerar que a matéria-prima empregada, do gênero pinus, possui baixa dureza superficial. Logo, é comum o aparecimento de mossas quando o painel está sujeito a impactos constantes, como, por exemplo, aqueles utilizados em 
lajes de piso sem revestimento. Portanto, durante a montagem de edificações em CLT, é necessário certo cuidado no manuseio dos painéis, evitando-se a ocorrência de danos e retrabalhos de acabamento após a montagem, no caso de painéis internos que não terão revestimento

Destaca-se, por fim, que, em se tratando do processo de construção industrializado, há necessidade de emprego de mão de obra qualificada na fabricação e montagem de painéis de CLT. Reforça-se, ainda, essa necessidade, tendo em vista o cuidado que se deve ter no manuseio dos painéis, conforme mencionado anteriormente. No entanto, no cenário brasileiro da construção civil, emprega-se largamente uma mão de obra desqualificada. No Brasil, os métodos tradicionais, utilizando mão de obra barata, sem grande preocupação com seu desempenho, são ainda vistos como vantajosos economicamente, justificando a posição do setor da construção civil como um dos que possuem mais baixa produtividade no país. Nesse sentido, aqui alega-se com frequência que, ao se buscar a industrialização na construção civil, grande parte da mão de obra nela empregada seria dispensada, acarretando um número elevado de desempregados. No entanto, na prática, essa industrialização geraria apenas a migração de parte da mão de obra do canteiro para a indústria, oferecendo ao trabalhador melhores condições de trabalho (BRUNA, 2002).

\section{O PROCESSO DE CONSTRUÇÃO EM CLT}

\subsection{Aspectos gerais}

$\mathrm{Na}$ condição de sistema construtivo industrializado, a construção de um edifício em CLT inicia-se na fábrica. Em um primeiro momento, os sarrafos de madeira que serão utilizados como matéria-prima passam pela etapa de triagem visual e mecânica, assim como medição de umidade de 12\% (+/- 2\%). A segunda etapa consiste na remoção dos defeitos, como grandes nós que se mostrem prejudiciais à estrutura. Os sarrafos são, então, emendados por meio de ligações denominadas finger joints, e, depois, as lâminas já emendadas são cortadas nas dimensões corretas para utilização em camadas longitudinais ou transversais. As emendas do tipo finger joint consistem em juntas com formato triangular, as quais maximizam a superfície de aplicação do adesivo estrutural para aderência das peças entre si (Figura 2). A etapa seguinte trata da montagem e prensagem dos painéis, realizada em prensas hidráulicas ou a vácuo. Para a prensagem, as lâminas são dispostas lado a lado e orientadas em uma mesma direção (Figura 3). É, então, aplicado o adesivo estrutural sobre a superfície da primeira camada de lâminas, em geral de forma mecanizada, posicionando-se em seguida uma nova camada acima e com orientação perpendicular à camada subjacente (Figura 4). Os principais adesivos estruturais utilizados são a Melanima Ureia Formaldeído (MUF) ou o poliuretano monocomponente. Ambos são resistentes a radiação solar, umidade e hidrólise (BRANDNER, 2013). Por fim, os painéis são cortados e usinados em equipamento com CNC (Figura 5).

Figura 2 - Emenda finger joint. Figura 3 - Aplicação do adesivo estrutural. Figura 4 - Montagem do painel. Figura 5 - Usinagem de um painel no equipamento com CNC.
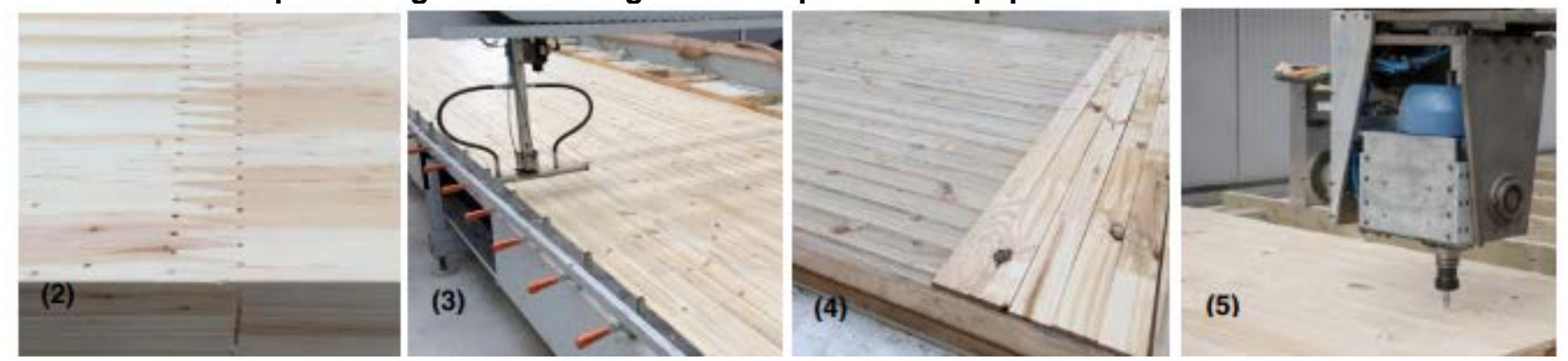

Fonte: da autora (2016)

Após a fabricação, os painéis são transportados ao local da obra. Devido às dimensões e ao peso, a montagem é realizada com o auxílio de gruas. Para isso, os painéis são identificados e posicionados de acordo com o planejamento previamente estabelecido em fábrica, ou seja, o plano de montagem. O esquema abaixo ilustra o processo de construção de edifícios em CLT (Figura 6). 
Figura 6 - Esquema ilustrando o processo construtivo de edifícios em CLT

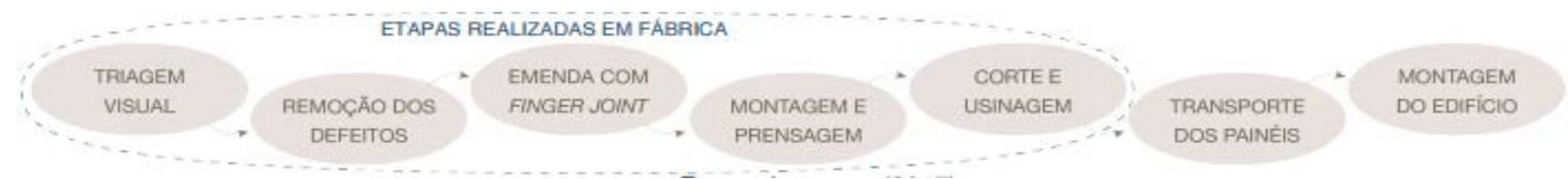

Fonte: da autora (2017)

\subsection{Conexões}

Para a conexão dos painéis entre si e com outras partes do edifício, são utilizados, majoritariamente, parafusos ou conectores metálicos (Figura 7). Dentre os conectores metálicos disponíveis no mercado, podem- se citar cantoneiras em aço galvanizado, chapas perfuradas e perfis extrudados em alumínio. Essas formas de conexão são válidas tanto para a fixação entre dois painéis de CLT quanto para a interface entre a estrutura de madeira e outros sistemas disponíveis no mercado. Painéis de CLT podem ser, dessa maneira, utilizados em estruturas mistas, por exemplo, com estruturas metálicas ou mesmo de concreto.

Figura 7 - Exemplos de conexões entre painéis de CLT. (a) e (b): Conexões por meio de parafusos. (c) e (d): Conexões por meio de conectores metálicos. (e) Conexão por meio de encaixe e parafuso.

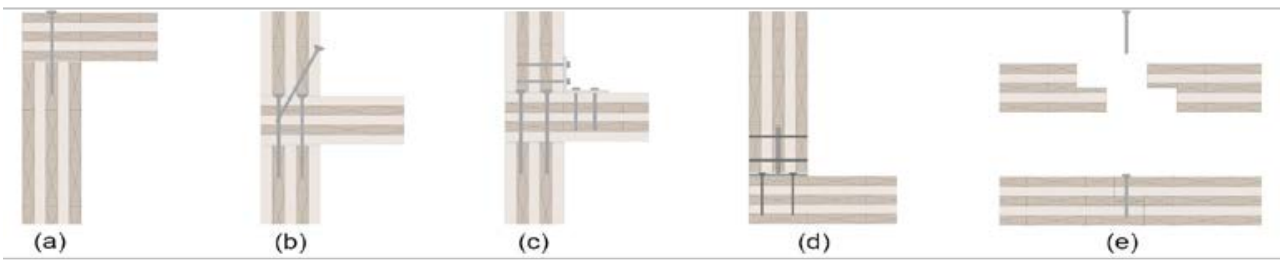

Fonte: da autora (2015)

\subsection{Instalações elétricas e hidráulicas}

A execução de instalações elétricas em edificações em CLT pode ser realizada de maneira aparente, com conduítes expostos, ou de forma oculta, com eletrodutos embutidos nos painéis de CLT. Para essa segunda forma de execução, os eletrodutos são usinados nos painéis por meio do equipamento de usinagem.

Instalações hidráulicas, entretanto, não podem ser alojadas no interior dos painéis maciços. Então, a construção de áreas molhadas é executada por meio de shafts dispostos na frente dos painéis. No caso de lajes de piso em CLT, as instalações devem correr abaixo delas, tornando-se necessária, em edificações de múltiplos pavimentos, a execução de um forro no ambiente inferior à área molhada.

\subsection{Acabamentos}

Após a montagem, é possível aplicar diferentes materiais de revestimento nas fachadas de edifícios em CLT, desde que se garantam adequados níveis de ventilação das fachadas. A ventilação protege os painéis de condensações e problemas de degradação precoce, pois, tendo em vista as características higroscópicas da madeira, os painéis são capazes de absorver, reter e liberar umidade (COSTA, 2013).

\section{O PROCESSO NACIONAL DE FABRICAÇÃO DE PAINÉIS DE CLT}

\subsection{Contextualização}

No Brasil, a produção do CLT ainda é muito recente. A primeira residência construída com painéis de CLT de que se tem conhecimento foi implantada na cidade de Tiradentes (MG) em 2012. (Figuras 8 e 9). 


\section{Figura 8 - Montagem da primeira residência em CLT no Brasil. Figura 9 - Residência finalizada.}
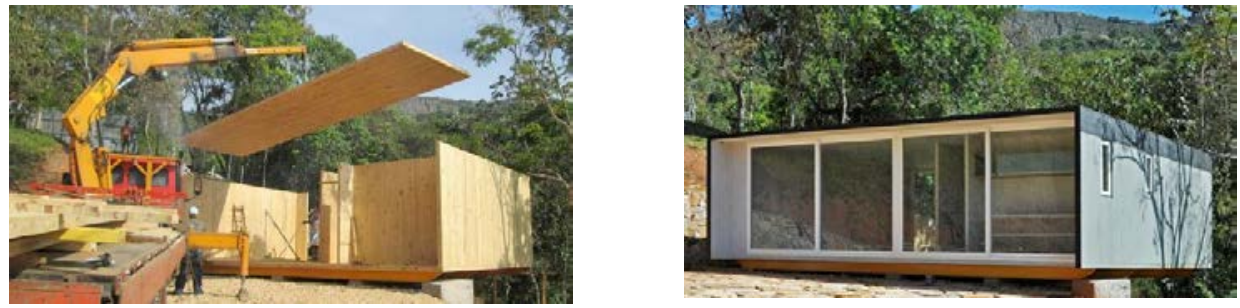

Fonte: imagens fornecidas pela empresa Crosslam (2012)

Alguns aspectos da fabricação nacional do sistema diferem das técnicas adotadas em outros países, consistindo o principal deles no tratamento preservativo da madeira empregada, tendo em vista o clima tropical brasileiro, que intensifica a biodeterioração do produto. Além disso, os painéis são aqui produzidos com comprimento máximo de $12 \mathrm{~m}$, distinguindo-se daqueles fabricados por algumas empresas estrangeiras.

A seguir, será detalhado o processo de fabricação nacional de painéis de CLT.

\subsection{Projeto dos painéis}

Após o recebimento do projeto arquitetônico, inicia-se outra etapa de projeto, que consiste na modelagem dos painéis de CLT. Esta é realizada no software de desenho AutoCAD 3D e os painéis são ajustados em conformidade com as dimensões do projeto da edificação. Para elementos com tamanhos que ultrapassam as dimensões máximas de fabricação, como lajes com mais de $12 \mathrm{~m}$, são projetados painéis distintos que serão conectados durante a montagem da edificação para configurar o elemento de maior dimensão.

O projeto dos painéis deve considerar, além do projeto arquitetônico já mencionado, questões de transporte e fabricação. A título de exemplo, pode-se citar uma parede com dimensões de $2,70 \mathrm{~m}$ de altura e $18 \mathrm{~m}$ de comprimento. Uma das opções possíveis para sua montagem seria fabricar um painel de $6 \mathrm{~m}$ e outro de $12 \mathrm{~m}$ de comprimento para se conectar as duas peças no local de montagem. No entanto, essa escolha não é a mais adequada para a fabricação, pois exige o ajuste da prensa e do equipamento de usinagem para dois tamanhos distintos. Uma opção mais vantajosa seria a fabricação de dois painéis com $9 \mathrm{~m}$ de comprimento por $2,70 \mathrm{~m}$ de largura, pois, assim, tanto a configuração da prensa quanto a do equipamento de usinagem seria realizada apenas uma vez para as duas peças.

Deve-se ressaltar, no entanto, que esse exemplo demonstra, de maneira simplificada, um dos aspectos que necessitam ser considerados na modelagem dos painéis. Naturalmente, mais fatores devem ser avaliados, como o veículo para transporte, os tamanhos e formatos dos demais painéis que serão utilizados na edificação, as condições de montagem, dentre outros de igual relevância.

Após a modelagem de todos os elementos a serem utilizados na edificação, esses são numerados e distribuídos nos painéis para que sejam fabricados, buscando-se maior economia e menor desperdício de material. Dessa forma, como ilustrado no esquema abaixo, de um único painel, é possível obter diversos elementos menores que irão configurar o edifício, como paredes, lajes, vigas, dentre outros (Figura 10).

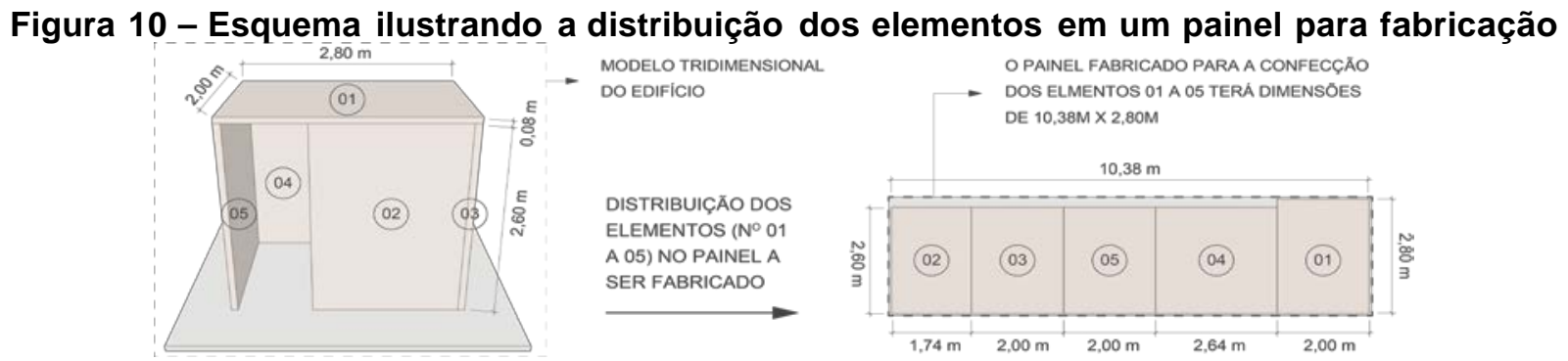

Fonte: da autora (2017) 
Observe-se que as etapas de fabricação, corte, usinagem, transporte dos painéis e montagem da edificação devem ser inteiramente planejadas antes de se iniciar a produção dos painéis em fábrica.

\subsection{Seleção da madeira}

A matéria-prima utilizada na fabricação nacional dos painéis é a madeira de pinus da espécie Pinus taeda, e os sarrafos de pinus adquiridos são provenientes de áreas de reflorestamento localizadas na região sul do país. A madeira é fornecida após secagem em estufa, adquirindo umidade de $12 \%(+/-2 \%)$, e já com aplicação de tratamento preservativo. Os sarrafos utilizados são tratados em autoclave, por meio da impregnação do preservante CCB (Borato de Cobre Cromatado), ou com inseticidas óleos solúveis, como cipermetrina.

O tratamento em autoclave com CCB evita o aparecimento de fungos manchadores e reduz a ação de bactérias, cupins e brocas (GONZAGA, 2006). No entanto, o pinus submetido a esse tratamento adquire uma tonalidade esverdeada, quando comparado àquele tratado apenas com inseticida, que mantém a coloração clara natural da madeira, variando de branca a amarelada. Esse segundo tipo de sarrafo é empregado, por uma questão estética, nas camadas superficiais dos painéis, quando assim determinado no projeto arquitetônico.

Contudo, a utilização apenas do inseticida, por ser aplicado na superfície dos sarrafos por meio de pincelamento, apresenta menor durabilidade em relação ao tratamento em autoclave, no qual o preservante é impregnado na matéria-prima. Logo, a opção pelo uso do inseticida pode exigir reaplicações futuras do produto.

\subsection{Remoção dos defeitos}

Os sarrafos de pinus armazenados na fábrica, em um primeiro momento, são submetidos a uma avaliação visual de controle de qualidade, e, então, são verificadas as características da madeira e removidos os defeitos que podem prejudicar a estrutura futuramente, como grandes nós ou pedaços de cascas.

\subsection{Emenda das lâminas}

A emenda dos sarrafos de pinus é realizada por meio de ligações denominadas finger joints (cf. item 3.1).

\subsection{Montagem e prensagem dos painéis}

As lâminas de pinus, já emendadas, são dispostas na prensa à vácuo lado a lado e orientadas em uma mesma direção, até se obter o comprimento desejado, ou a largura, para o painel. É então aplicado, de forma automatizada, o adesivo estrutural sobre a superfície dessa primeira camada de lâminas, posicionando-se em seguida uma nova camada acima e com orientação perpendicular à camada subjacente. O adesivo estrutural utilizado é monocomponente de poliuretano, isento de solventes ou formaldeídos.

A prensa à vácuo utilizada na fabricação nacional possui um tamanho de $12 \mathrm{~m}$ de comprimento por $3 \mathrm{~m}$ de largura. Consequentemente, os painéis confeccionados podem atingir dimensões de no máximo $12 \mathrm{~m} \times 3 \mathrm{~m}$. Já as lâminas de pinus possuem espessura de $19 \mathrm{~mm}, 20 \mathrm{~mm}, 30 \mathrm{~mm}$ ou $40 \mathrm{~mm}$. Assim, os painéis de CLT finalizados podem variar de $57 \mathrm{~mm}$ (3 camadas de lâminas de 19mm) até $250 \mathrm{~mm}$ (7 camadas, sendo 4 de lâminas de $40 \mathrm{~mm}$ e 3 de lâminas de $30 \mathrm{~mm}$ ).

\subsection{Corte e usinagem dos painéis}

O processo de produção é finalizado com o corte e a usinagem dos painéis em um equipamento com CNC. Para a usinagem dos painéis, utiliza-se o modelo tridimensional realizado previamente no software de modelagem durante a etapa de projeto dos painéis (cf. item 4.1). O modelo tridimensional de cada elemento que irá configurar a edificação é exportado, individualmente, para o software do 
equipamento de usinagem, onde também são programados os movimentos que deverão ser executados para cortar e usinar o painel.

Consequentemente, as aberturas de portas e janelas, canaletas de passagem de eletrodutos e outras necessárias para instalações prediais são executadas previamente em fábrica. Ressalta-se, nesse sentido, a necessidade de se detalhar o projeto arquitetônico de maneira minuciosa antes do início do processo de produção dos painéis, incluindo projetos complementares como elétrico e hidráulico, tendo em vista o melhor aproveitamento das vantagens oferecidas por um sistema industrializado e fabricado digitalmente.

\section{DISCUSSÃO: O PROJETO ARQUITETÔNICO E A FABRICAÇÃO DE PAINÉIS DE CLT}

Tendo em vista o exposto, torna-se evidente a estreita relação entre todas as fases de construção de edificações em CLT, que devem ser planejadas conjuntamente de maneira a otimizar o processo construtivo.

O emprego do equipamento de usinagem com CNC possibilita um altíssimo grau de personalização ou customização no processo de produção, o qual se contrapõe à usual associação de sistemas construtivos industrializados a rigidez e uniformidade. Ainda assim, algumas decisões tomadas na fase de projeto da edificação impactam diretamente no processo de confecção dos painéis, interferindo na produtividade da produção e na otimização da construção. São apresentados a seguir os principais aspectos levantados.

\subsection{Dimensões estabelecidas no projeto arquitetônico}

Como mencionado, é possível a execução de painéis de CLT em qualquer dimensão e formato. Contudo, atentar-se para as dimensões máximas obtidas na linha de produção pode auxiliar o processo de fabricação dos painéis. A alteração da altura de uma parede de $3,05 \mathrm{~m}$ para $3,00 \mathrm{~m}$, por exemplo, pode não acarretar grandes modificações no projeto arquitetônico, mas, em contrapartida, permitirá produzir o elemento em questão com apenas um painel, otimizando a fabricação e a montagem. Não é necessário, no entanto, restringir o projeto a dimensões modulares ou padronizadas, já que o emprego do equipamento de usinagem com CNC permite alto grau de personalização, sem que se perca com isso a otimização da produção.

\subsection{Estética dos painéis}

Painéis de CLT podem ser utilizados sem revestimento em ambientes internos. Caso essa seja a opção determinada no projeto arquitetônico, deve-se definir previamente qual a aparência desejada para os painéis, conforme descrito no item 4.3 .

\subsection{Projetos complementares}

O detalhamento de projetos complementares, como elétricos, hidráulicos, luminotécnicos, dentre outros, é essencial para a maior otimização da produção, tendo em vista que caixas elétricas, furos para passagem de tubulação hidráulica ou mesmo canaletas para passagem de eletrodutos podem ser usinados ainda em fábrica, durante a última etapa de fabricação dos painéis, por meio do equipamento de usinagem com CNC.

\section{CONCLUSÃO}

Como em qualquer outro sistema construtivo, para que seja alcançada maior otimização na construção de um edifício com painéis de CLT, é importante que todos os profissionais envolvidos no processo conheçam as tecnologias nele empregadas.

Dessa maneira, o presente artigo procurou apresentar o processo de fabricação de painéis de CLT, com ênfase na produção nacional do sistema. Com base no estudo das etapas de confecção desses painéis, foi possível levantar as principais decisões de projeto que impactam na produção do sistema, 
possibilitando gerar subsídios para o desenvolvimento de projetos nos quais será empregada essa inovadora tecnologia construtiva.

Sabe-se da importância do conhecimento das características de desempenho de um sistema construtivo inovador para o usuário, e a pesquisa, no momento, está voltada para a viabilidade do estudo e análise da durabilidade e dos desempenhos térmico e estrutural dos painéis, por meio de ensaios laboratoriais e cálculos. Tais resultados trarão maior embasamento técnico e científico para a caracterização da tecnologia analisada.

Por fim, como já apontado, muitos são os benefícios vindos do emprego de painéis de CLT e, dentre eles, podem-se citar a construção industrializada, a utilização da madeira como matéria-prima e as possibilidades plásticas viabilizadas pela utilização de um equipamento de usinagem com CNC, muito embora, quando não respeitados os princípios de industrialização e as características e limitações do sistema em questão, deixa-se de maximizar as vantagens relacionadas à racionalização apresentadas pela tecnologia. Porém, se planejado o emprego do sistema construtivo inovador CLT de maneira a se compreender a relação existente entre suas etapas construtivas, apresenta-se ele como uma alternativa extremamente promissora na construção civil.

\section{REFERÊNCIAS}

BARILLARI, T. C.; FREITAS, V. P. Preservação. Revista da Madeira. v. 68. 2002. Disponível em: $<$ http://www.remade.com.br/br/revistadamadeira_materia.php?num=264\&subject=Preserva\%E7\%E3o\&title $=$ Pre serva\%E7\%E3o>. Acesso em: maio de 2017 .

BRANDNER, R. Production and Technology of Cross Laminated Timber (CLT): A state-of-the- art Report. 2013. <http://costfp1004.holz.wzw.tum.de/fileadmin/tu/wz/costfp1004/Theme_I_Product_and__Testing.pdf>. Acesso em: abril de 2017.

BRUNA, P. J. V. Arquitetura, Industrialização e Desenvolvimento. São Paulo: Editora Perspectiva e Editora da Universidade de São Paulo, 2002.

COSTA, A. A. P. Construção de edifícios com Cross Laminated Timber (CLT). Dissertação (Mestrado) - Faculdade de Engenharia, Universidade do Porto. Porto, Portugal, 2013.

FRANGI, A.; BOCHICCHIO, G.; CECCOTTI, A.; LAURIOLA, M. P. Natural Full-Scale Fire Test on a 3 Storey

XLam Timber Building. 10 $0^{\text {th }}$ World Conference on Timber Engineering. Miyazaki, Japão, 2008.

GAUZIN-MÜLLER, D. Arquitetura Ecológica. São Paulo: Editora Senac São Paulo, 2011. GONZAGA, A. L. Madeira: uso e conservação. Brasília: IPHAN/Monumenta, 2006.

KARACABEYLI, E.; DOUGLAS, B. CLT Handbook. U.S. Edition. Pointe-Claire: FPInnovations, 2013.

MOLINA, J. C.; CALIL JUNIOR, C. Sistema construtivo em wood frame para casas de madeira. Semina: Ciências Exatas e Tecnológicas, v. 31, n. 2. Londrina, 2010, pág. 143-156.

SABATTINI, F. H. Desenvolvimento de métodos, processos e sistemas construtivos : formulação e aplicação de uma metodologia. Tese (Doutorado) - Escola Politécnica, Universidade de São Paulo. São Paulo,

1989.

SILVA, C.; BRANCO, J. M.; LOURENÇO, P. B. MLCC na Construção em Altura. Congresso Construção. Coimbra, 2012.

STAUDER, C. Cross-Laminated Timber: An analysis of the Austrian industry and ideas for fostering its development in America. Fachhochschule Salzburg: University of Applied Sciences. 2013. Disponível em:

<https://static1.squarespace.com/static/559921a3e4b02c1d7480f8f4/t/585c32fa6a4963601460c3f0/148243 7399

758/Stauder.pdf>. Acesso em: abril de 2017.

VAZ, G. Norma técnica sobre o wood frame deve entrar em consulta pública ainda neste semestre. PilNIWeb, 2017. Disponível em: <http://construnormas.pini.com.br/engenharia-instalacoes/noticias/normatecnica-sobre-wood-frame-deve-entrar-em-consulta-publica-379824-1.aspx>. Acesso em: maio de 2017. 